\title{
VISUAL EXPERIENCE DURING CATARACT SURGERY
}

\author{
I. E. MURDOCH and P. SZE \\ London
}

\begin{abstract}
SUMMARY
Fifty-six sequential patients undergoing cataract surgery using local anaesthesia were invited to complete a questionnaire recording their visual experience during the surgery. A majority had peribulbar anaesthesia; none had pre- or per-operative sedation. Fifty-four of the patients could see with their eye during the surgery. Two of these patients could perceive only a bright light; the remainder recorded colours $(80 \%)$, followed by movements $(68 \%)$, flashes $(66 \%)$, abstract colour images $(55 \%)$ and perception of objects $(20 \%)$. In two-thirds the brightness of the light changed during the course of the operation (most commonly getting brighter) and in onethird the colours perceived changed during the operation. Pictures were drawn by 22 of the patients of their experience during the surgery.
\end{abstract}

Local anaesthesia is increasingly used as the method of anaesthesia for cataract surgery. When asked for informed consent for this procedure patients not infrequently enquire whether they will have any visual experience during the surgery. In order to attempt to answer this query we performed a small trial.

\section{METHOD}

Sequential patients undergoing routine extracapsular cataract extractions with intraocular lens implantation as day cases at Moorfields Eye Hospital were invited to complete a questionnaire recording their visual experience during the surgery. Patients with other significant concurrent ocular morbidity were excluded from the study. None of the patients received pre-operative or peri-operative anxiolytics or other drugs which might impair cognitive skills. The questionnaire was completed by trained ophthalmic nurses immediately the patient returned to the day-care ward (about 20 minutes after completion of surgery). All operative procedures were uncomplicated. The method of anaesthesia employed was recorded in addition to eight questions as an introduction to individuals being invited to record their visual experience in their own words. Finally

Correspondence to: I. E. Murdoch, Moorfields Eye Hospital, City Road, London EC1V 2PD, UK. patients were invited to draw a picture of what they saw during the operation.

\section{RESULTS}

A total of 56 patients participated in the study. They had a median age of 71.5 years (range 33-89 years). In 14 cases the nature of the local anaesthetic given was not recorded; 31 had peribulbar and 11 retrobulbar anaesthesia. Twentyfour of the patients recorded vision after administration of the anaesthetic but prior to surgery; one patient made the point he could see with the other eye, and another saw a cheese grater. Five patients had visual experiences which involved coloured movements (two pink, one orange, one unspecified and the other red, yellow and purple); the remainder had largely unchanged vision. There was no difference between visual perception at this stage with respect to method of anaesthesia (chi-squared $=0.99, p=$ 0.32 ).

Two patients saw nothing during their operation, both of whom had received retrobulbar anaesthetic. Two of the remaining fifty-four of the patients saw only light during the operation (one of these had received retrobulbar anaesthetic and the method of anaesthesia was not recorded in the other case). A chi-squared test shows this to suggest a significant association of visual loss with retrobulbar anaesthesia (chi-squared $=9.1, p=0.003$ ). Of the remaining patients, 45 (80\% total) saw colours, $38(68 \%)$ saw movements and 37 (66\%) saw flashes. Examination of the free text descriptions showed abstract colour images to be the most common visual experience $(31$, or $55 \%)$, with instrument flashes or 'wires' next most common (11, or 20\%). Rainbows, Picasso drawings, fingerprints, light on water, liquorice allsorts sweets, a kaleidoscope and sky with clouds were images used to describe the experience. Six individuals recorded being able to see hands or people. There did not appear to be a tendency towards any one particular colour in those mentioned (red/pink 13, blue/ purple 11, yellow/green 7, white/silver 12).

During the course of the operation $35(64 \%)$ individuals noticed a change in brightness. In 25 the light became brighter and in 9 it became less bright. Seventeen individuals noticed other changes through the course of the oper- 


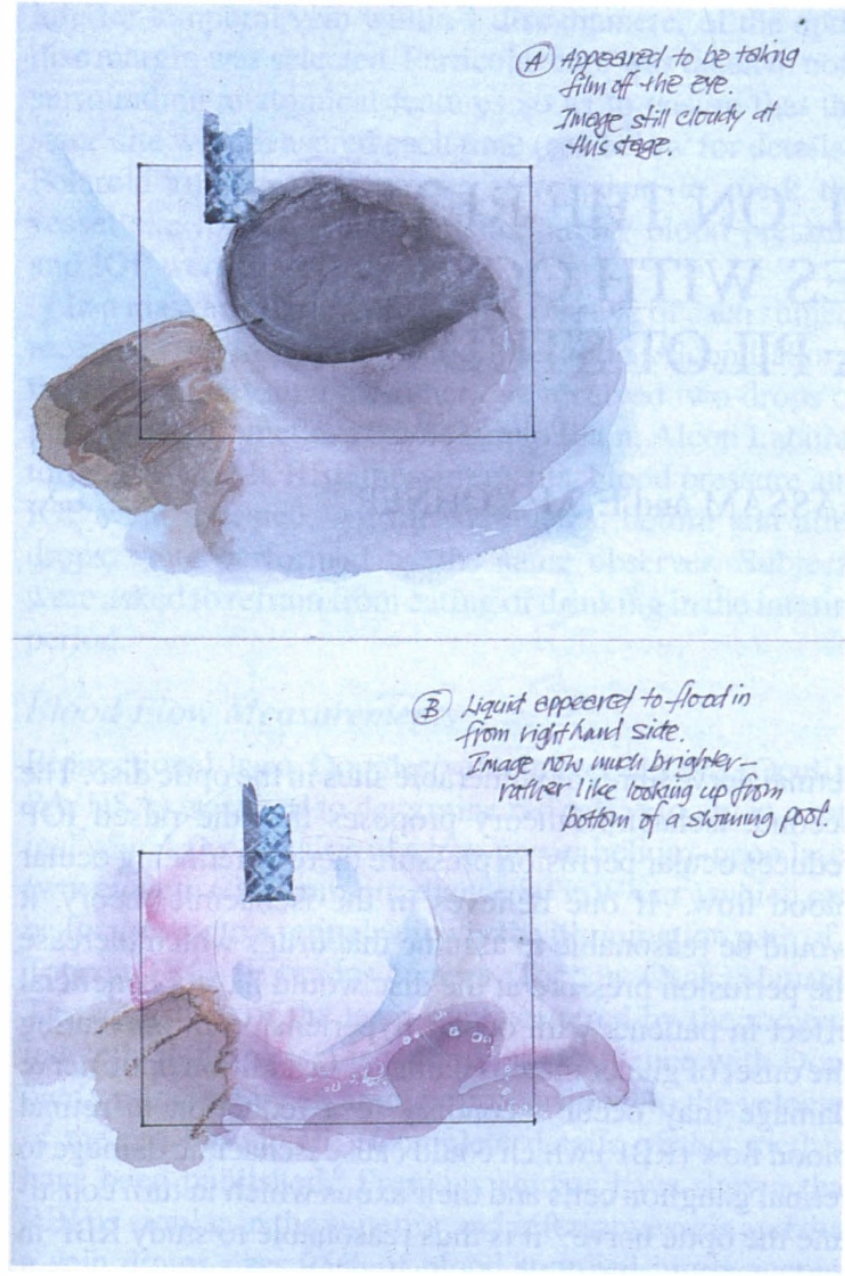

Fig. 1. The subjective experience of cataract surgery under local anaesthesia as illustrated by one patient.

ation. Eleven of these recorded a change in the colours perceived whilst the remainder noticed movements.

Pictures were drawn by 22 of the patients, and these varied as much as the descriptions. Some showed just white/silver boxes or circles; the majority, however, showed rainbow streaks or circles with a (usually central) circle or square of one colour. A final feature recorded by several patients was a grid-like appearance within a square. Fig. 1 shows the drawings of one artist illustrating his visual experience during surgery.

\section{DISCUSSION}

We have found four reports of visual acuity assessment after administration of local anaesthesia. The first paper by Levin and O'Connor ${ }^{1}$ was prompted by the observation that several of their patients said they could see the surgical instruments with the operated eye during intraocular surgery. All 26 of their patients had diminished visual acuities after their local anaesthetic injection and 19 could see the instruments during their surgery. Brent and Singh ${ }^{2}$ similarly reported on visual acuities of 30 consecutive patients who received retrobulbar injections. In 4 patients the acuities were unaltered following anaesthetic administration and in the remainder the acuities were reduced by an average of just under three lines on a Jaeger near chart. Recently Talks et al. ${ }^{3}$ reported that 20 patients given peribulbar anaesthesia all had a reduction in visual acuity, with 5 losing light perception. Their method of anaesthetic administration differs from ours in that a large volume is injected and an injection is given medial to the caruncle. Peri-operatively 4 of their patients reported visual images described as 'colours', 'floating liquid' or 'circles of light'; none saw instruments during their surgery. Finally, Scott et al. ${ }^{4}$ reported similar results to Talks et al. in a letter. They looked at 50 patients given peribulbar anaesthesia and noted visual loss in 11 cases.

The finding that, where profound visual loss did occur, it was associated with retrobulbar anaesthesia, is not surprising from an anatomical viewpoint. It is in keeping with the findings of Doden and Bopp, ${ }^{5}$ Verma et al. ${ }^{6}$ and Ropo et $a l^{7}$ who all reported extinction of visual evoked potentials (VEP) after retrobulbar anaesthesia. The patients who received periocular anaesthesia in the study by Ropo et al. had no clear-cut effect on their VEP resulting from the anaesthetic.

To our knowledge this is the first detailed report of subjective vision during cataract surgery. The results may help in informed consent of patients about to undergo such a procedure.

We would like to thank Mr J. E. Wright and Mr G. Rose for their help in this study, in addition to the other ophthalmologists and nurses who helped in caring for the patients. Mr Neil Moult kindly painted the illustration for this communication, based on his own surgical experience.

Key words: Local anaesthesia, Peribulbar, Retrobulbar, Visual experience.

\section{REFERENCES}

1. Levin ML, O'Connor PS. Visual acuity after retrobulbar anaesthesia. Ann Ophthalmol 1989;11:337-9.

2. Brent BD, Singh $\mathrm{H}$. The effect of retrobulbar anaesthesia on visual acuity in planned extracapsular cataract extraction. Ophthalmic Surg 1991;2:392-5.

3. Talks SJ, Chong NHV, Gibson JM, Francis IR. Visual acuity and pupillary reactions after peribulbar anaesthesia. $\mathrm{Br} \mathbf{J}$ Ophthalmol 1994;78:41-3.

4. Scott RAH, Acharya PA, Jake Man CM, Perry SR. Peribulbar anaesthesia. Br J Ophthalmol 1994;78:592.

5. Doden W, Bopp M. Optikusblockade durch retrobulbäre Anaesthesie. Klin Monatsbl Augenheilk 1984;184:311-2.

6. Verma L, Arora R, Kumar A. Temporary conduction block of optic nerve after retrobulbar anaesthesia. Ophthalmic Surg 1990;21:109-12.

7. Ropo A, Ruusuvaara P, Setala K. Visual evoked potentials after retrobulbar or periocular anaesthesia. Br J Ophthalmol 1992;76:541-4. 